\title{
Pelatihan konselor pemeriksaan sindrome metabolic pengurus majlis taklim masjid al mustaqim di Sanggrahan Kasihan Bantul
}

\author{
Dika Rizki Imania1, Mohammad Ali Imron² \\ ${ }^{1}$ Fisioterapi/Ilmu Kesehatan, Universitas 'Aisyiyah Yogyakarta \\ ${ }^{2}$ Fisioterapi/Ilmu kesehatan, Universitas 'Aisyiyah Yogyakarta \\ *Email: dikarizki@unisayogya.ac.id*, aliimron@unisayogya.ac.id
}

\begin{abstract}
ABSTRAK
World Health Organization (WHO) 2013 mengemukakan bahwa non-communicable disease (NCDs) merupakan tantangan kesehatan terbesar pada abad 21. Dari seluruh angka morbiditas NCDs, jumlah cardiovascular disease (CVD) merupakan yang terbesar yaitu 17,3 juta jiwa/tahun. Berkaitan dengan diabetes, pada sebagian penderita diabetes tipe dua atau intoleransi glukosa, didapatkan serangkaian faktor risiko yang muncul bersamaan dengan faktor risiko CVD. Fenomena tersebut disebut dengan kejadian sindrom metabolik. Memberikan pengetahuan dan keterampilan kepada kader untuk melakukan screening sindrom metabolik sehingga pengurus maupun peserta majlis taklim bisa mengubah pola hidup menjadi lebih sehat lagi. Metode yang digunakan adalah koordinasi, pemberdayaan sumber daya manusia, promosi dan sosialisasi kader, pelatihan kader, penyusunan buku pedoman kader, pelaksanaan jasa layanan kesehatan, evaluasi kegiatan, dan pelaporan pencatatan kegiatan. Menghasilkan empat kader terlatih dan hasil pada peserta bahwa kategori usia dewasa akhir, lansia akhir dan manula lebih rentan terkena Sindrom Metabolik. Hasil akhir yang diharapkan dari kegiatan ini adalah meningkatkan kesadaran masyarakat untuk mengetahui pentingnya pengetahuan tentang sindrome metabolik. Pemberian penyuluhan dan pelatihan kader dalam screening sindrome metabolik dapat menambah pengetahuan dan wawasan pengurus majlis taklim masjid Al Mustaqim Di Sanggrahan Ngestiharjo Kasihan Bantul.
\end{abstract}

Kata Kunci : pelatihan; kader; sindrom metabolik

\section{Metabolic syndrome examination training for the management of the Al Mustaqim mosque taklim majlis at Sanggrahan Kasihan Bantul}

\begin{abstract}
The World Health Organization (WHO) in 2013 stated that non-communicable diseases (NCDs) are the biggest health challenges in the 21 st century. Of all the morbidity rates for NCDs, the number of cardiovascular disease (CVD) is the largest at 17.3 million people/year. With regard to diabetes, in some patients with type 2 diabetes or glucose intolerance, a series of risk factors co-occur with CVD risk factors. This phenomenon is known as the incidence of metabolic syndrome. To provide knowledge and skills to cadres to screen for metabolic syndrome so that administrators and taklim majlis participants can change their lifestyle to be healthier. The methods used are coordination, empowerment of human resources, promotion and socialization of cadres, training of cadres, preparation of cadre manuals, implementation of health services, evaluation of activities, and reporting of activity records. The final expected result of this activity is to increase public awareness to know the importance of knowledge about metabolic syndrome. Providing counseling and training for cadres in screening for metabolic syndrome can increase the knowledge and insight of the management of the Al Mustaqim Mosque at Sanggrahan Ngestiharjo Kasihan Bantul.
\end{abstract}

Keywords : cadre; metabolic syndrome; training

\section{PENDAHULUAN}

World Health Organization (WHO) 2013 mengemukakan bahwa non-communicable disease (NCDs) merupakan tantangan kesehatan terbesar pada abad 21. Dari seluruh angka morbiditas NCDs, jumlah cardiovascular disease (CVD) merupakan yang terbesar yaitu 17,3 juta jiwa/ tahun. Berkaitan dengan diabetes, pada sebagian 
penderita diabetes tipe dua atau intoleransi glukosa, didapatkan serangkaian faktor risiko yang muncul bersamaan dengan faktor risiko CVD. Fenomena tersebut disebut dengan kejadian sindrom metabolik. "Simbol" atau Sindrom Metabolik (SM) merupakan kelainan metabolik kompleks yang diakibatkan oleh peningkatan obesitas (Amigo, 2017).

Saat ini, SM telah menjadi masalah kesehatan masyarakat dan tantangan klinis di seluruh dunia berkaitan dengan urbanisasi (perubahan gaya hidup dan pola makan), asupan energi yang berlebihan, peningkatan kejadian obesitas dan gaya hidup sedentary serta terkait dengan dampak yang ditimbulkannya. Kriteria diagnosis SM saat ini mengacu pada kriteria diagnosis WHO, National Cholesterol Education Program (NCEP), Adult Treatment Panel (ATP) III, meliputi obesitas abdomen, peningkatan kadar trigliserida darah, penurunan kadar kolesterol baik (atau highdensity lipoprotein/ HDL), tekanan darah tinggi, dan peningkatan kadar glukosa darah. SM secara umum diartikan sebagai memenuhi 3 dari 5 dari kriteria di atas. Berdasarkan penelitian tersebut, maka program kemitraan masyarakat pada pengurus Majlis Taklim Masjid AL Mustaqim bertujuan untuk memberikan pengetahuan dan keterampilan kepada kader untuk melakukan screening sindrom metabolik sehingga pengurus maupun peserta majlis taklim bisa mengubah pola hidup menjadi lebih sehat lagi.

\section{METODE}

Metode yang digunakan pada kegiatan pengabdian masyarakat ini digunakan untuk merealisasikan program tersebut adalah sebagai berikut :

1. Melakukan studi pendahuluan untuk melihat fenomena kesehatan yang real terjadi pada pengurus dan peserta majlis taklim

2. Metode koordinasi Kegiatan ini bertujuan untuk mendapatkan dukungan dari penentu kebijakan pengurus majlis taklim terhadap kelancaran dan keberlangsungan pembentukan pengelola dan kader dalam pelayanan kesehatan.

3. Metode pemberdayaan sumber daya manusia Kegiatan ini bertujuan untuk menyiapkan dan memberdayakan SDM (Pengeloladan Kader pelayanan Kesehatan)

4. Metode promosi dan sosialisasi adanya kader kesehatan yang telah terbentuk dalam melakukan screening sindrom metabolik Kegiatan ini bertujuan untuk memperkenalkan adanya kader terlatih kepada semua anggota pengajian dan masyarakat sekitar serta pihak yang terkait dalam rangka memperluas akses dan pengembangan dukungan serta jaringan.

5. Metode pelatihan kader kesehatan siap guna. Metode ini bertujuan untuk menyiapkan kader kesehatan yang baik dan berkualitas dalam memberikan pelayanan kesehatan mampu memotivasi pengurus maupun peserta majlis taklim agar sadar kesehatan.

6. Metode penyusunan buku panduan atu modul Pelaksanaan menyusun modul 
atau buku panduuan ini sebagai pedoman para kader dalam melakasanakan screening sindrom metabolic

7. Metode pembuatan video Bukti proses pelaksanaan pelatihan screening sindrom metabolic dengan membuat video

8. Metode pelaksanaan jasa layanan kesehatan Pelaksanaan jasa layanan kesehatan dilakukan secara bergantian oleh kader-kader kesehatan yang sudah terlatih sesuai jadwal yang dibentuk. Screening sindrom metabolik serta penyuluhan kesehatan dilakukan rutin pada kelompok pengajian dan masyarakat sekitar setiap 1 bulan sekali.

9. Metode Monitoring dan Evaluasi Pelaksanaan kegiatan akan dilakukan monitoring dan evaluasi oleh pengelola program. Monitoring dan evaluasi digunakan untuk mendeteksi adanya hambatan pada pelaksanaan program. Harapannya hasilnya dapat digunakan untuk perbaikan pada pelaksanaan program berikutnya.

10. Metode Pencatatan dan Pelaporan Pencatatan dan pelaporan kegiatan dilakukan oleh pelaksana kegiatan dan pengurus. Hasil pencatatan dan pelaporan tersebut dapat dijadikan data yang dapat digunakan untuk perbaikan dan pengembangan program.

Langkah-langkah Pelaksanaan Dalam mendukung realisasi metode yang pengusul tawarkan, maka pengusul harus melakukan beberapa langkah yaitu:

1. Pengusul bersama dengan mahasiswa melihat fenomena kesehatan yang real terjadi pada pengurus dan peserta majlis taklim

2. Pengusul berinisiatif melakukan pertemuan dengan pengurus majlis taklim menyampaikan fenomena kesehatan yang ditemukan dan rencana pembentukan kader kesehatan.

3. Melakukan sosialisasi tentang pengelola pelayanan kesehatan yang telah dibentuk kepada pengurus serta menjaring kader kesehatan minimal 2 kader kesehatan.

4. Pengelola dan kader kesehatan yang sudah terbentuk menandatangani kesanggupan untuk berperan aktif dalam memberikan layanan kesehatan

5. Melakukan pelatihan dan pembekalan bagi kader kesehatan yang sudah terpilih.

6. Menyusunan buku panduan atau modul sebagai pedoman para kader dalam melakasanakan screening sindrom metabolic

7. Membuatan video bukti proses pelaksanaan pelatihan screening sindrom metabolic dengan membuat video

8. Menjadwalkan pelaksanaan jasa layanan kesehatan Pelaksanaan jasa layanan kesehatan dilakukan secara bergantian oleh kader-kader kesehatan yang sudah terlatih sesuai jadwal yang dibentuk. Screening sindrom metabolik serta penyuluhan kesehatan dilakukan rutin pada kelompok pengajian dan masyarakat sekitar setiap 1 bulan sekali.

9. Monitoring dan Evaluasi Pelaksanaan kegiatan akan dilakukan monitoring dan evaluasi oleh pengelola program. 
Monitoring dan evaluasi digunakan untuk mendeteksi adanya hambatan pada pelaksanaan program. Harapannya hasilnya dapat digunakan untuk perbaikan pada pelaksanaan program berikutnya.

10. Metode Pencatatan dan Pelaporan Pencatatan dan pelaporan kegiatan dilakukan oleh pelaksana kegiatan dan pengurus. Hasil pencatatan dan pelaporan tersebut dapat dijadikan data yang dapat digunakan untuk perbaikan dan pengembangan program

\section{HASIL DAN PEMBAHASAN}

Hasil

Pelatihan kepada 4 kader kesehatan siap guna yang telah ditentukan oleh penentu kebijakan dalam kepengurusan majlis taklim yang bertujuan untuk memiliki kader kesehatan yang baik dan berkualitas dalam memberikan pelayanan kesehatan mampu memotivasi pengurus maupun peserta majlis taklim agar sadar kesehatan. Pelaksanaan pelatihan 4 kader dalam melakukan screening sindrom metabolic yaitu pada bulan Maret dan Juni 2021 di Hall Masjid Al Mustaqim, setelah berlatih beberapa kali dan telah siap maka untuk melakukan pemeriksaan kepada peserta.

Hasil pelaksanaan penyuluhan dan screening syndrome metabolik pada kelompok majlis taklim Al Mustaqim dilakukan 2 kali pada bulan maret 2021 dengan total 40 peserta dan bulan juni 2021 total 36 peserta yang terdiri dari laki-laki maupun perempuan dan ratarata usia lebih dari 25 tahun hingga 65 tahun ke atas.
Kelompok pengajian ini sudah lama terbentuk dimana pesertanya adalah masyarakat sekitar. Sebagian besar adalah ibu rumah tangga, pegawai swasta, guru, dimana jarang sekali melakukan pemeriksaan kesehatan secara rutin dikarenakan sibuknya aktifitas serta minimnya pengetahuan tentang kesehatan terutama tentang sindrom metabolic. Berikut klasifikasi peserta sesuai kategori.

\section{Pembahasan}

Menurut (Nurzakiah et al., 2021) Sindrom Metabolik adalah kumpulan gangguan metabolik yang dapat dilihat dari beberapa parameter yaitu, kadar gula darah, trigliserida darah, obesitas sentral, kadar HDL, dan tekanan darah. Menurut Menurut (Soegondo \& Purnamasari, 2010) Penyebab Sindrom Metabolik belum dapat diketahui secara pasti. Suatu hipotesis menyatakan bahwa penyebab primer dari Sindrom Metabolik adalah resistensi insulin.

Faktor risiko untuk Sindrom Metabolik adalah hal-hal dalam kehidupan yang dihubungkan dengan perkembangan penyakit secara dini. Ada berbagai macam faktor risiko SM, antara lain adalah gaya hidup (pola makan, konsumsi alkohol, rokok, dan aktivitas fisik), sosial ekonomi dan genetik serta stres.

Menurut (Bimandama \& Soleha, 2016) ada tiga definisi SM yang telah diajukan, yaitu definisi WHO, NCEPATP III dan International Diabetes Federation (IDF). Ketiga definisi tersebut memilik komponen utama yang sama dengan penentuan kriteria yang berbeda. Kriteria yang sering digunakan 
untuk menilai pasien SM adalah kriteria NCEP-ATP III. . Kriteria diagnosis NCEP-ATP III menggunakan parameter yang lebih mudah untuk diperiksa dan diterapkan oleh para klinisi sehingga dapat dengan lebih mudah mendeteksi SM.

Tabel 1: Kategori Tekanan Darah

\begin{tabular}{ccc}
\hline $\begin{array}{c}\text { Klasifikasi Tekanan } \\
\text { Darah }\end{array}$ & TDS $(\mathbf{m m H g})$ & TDD $(\mathbf{m m H g})$ \\
\hline Optimal & $<120$ & $<80$ \\
\hline Normal & $120-129$ & $80-84$ \\
\hline High Normal & $130-139$ & $85-89$ \\
\hline Hipertensi tingkat 1 & $140-159$ & $90-99$ \\
\hline Hipertensi tingkat 2 & $160-179$ & $100-109$ \\
\hline Hipertensi tingkat 3 & 180 & 110 \\
\hline
\end{tabular}

(Setiadi \& Halim, 2018)

Tabel 2: Kategori Kolestrol

\begin{tabular}{|c|c|}
\hline Klasifikasi & Interpretasi \\
\hline \multicolumn{2}{|l|}{ Total Cholesterol (TC) } \\
\hline$<200 \mathrm{mg} / \mathrm{dl}$ & Optimal \\
\hline $200-239 \mathrm{mg} / \mathrm{dl}$ & Agak tinggi \\
\hline$>240 \mathrm{mg} / \mathrm{dl}$ & Tinggi \\
\hline \multicolumn{2}{|l|}{ Low-Density Lipoprotein } \\
\hline Cholesterol (LDL-C) & Optimal \\
\hline$<100 \mathrm{mg} / \mathrm{dl}$ & Mendekati \\
\hline $100-129 \mathrm{mg} / \mathrm{dl}$ & optimal \\
\hline $130-159 \mathrm{mg} / \mathrm{dl}$ & Agak tinggi \\
\hline $160-189 \mathrm{mg} / \mathrm{dl}$ & Tinggi \\
\hline$>190 \mathrm{mg} / \mathrm{dl}$ & Sangat tinggi \\
\hline \multicolumn{2}{|l|}{ High-Density Lipoprotein } \\
\hline Cholesterol (HDL-C) & Rendah \\
\hline$<40 \mathrm{mg} / \mathrm{dl}$ & Tinggi \\
\hline$>40 \mathrm{mg} / \mathrm{dl}$ & \\
\hline \multicolumn{2}{|l|}{ Triglycerides (TG) } \\
\hline$<150 \mathrm{mg} / \mathrm{dl}$ & Normal \\
\hline $150-199 \mathrm{mg} / \mathrm{dl}$ & Agak tinggi \\
\hline $200-499 \mathrm{mg} / \mathrm{dl}$ & Tinggi \\
\hline$\geq 500 \mathrm{mg} / \mathrm{dl}$ & Sangat tinggi \\
\hline
\end{tabular}

(Setiadi \& Halim, 2018)

Tabel 3: Kategori Gula Darah

\begin{tabular}{ccc}
\hline \multicolumn{3}{c}{ Glukosa Darah Sewaktu } \\
\hline Baik & Sedang & Buruk \\
\hline $\mathbf{1 1 0}-<\mathbf{1 4 5} \mathbf{~ m g / D l}$ & $145-179$ & $>180 \mathrm{mg} / \mathrm{dL}$ \\
& $\mathrm{mg} / \mathrm{dL}$ & \\
\hline
\end{tabular}

(Amir, 2015)

Tabel 4: Lingkar Pinggang Untuk Mengidentifikasi Subjek Dengan Sindrome

Metabolik

\begin{tabular}{cc}
\hline \multicolumn{2}{c}{ Lingkar Pinggang } \\
\hline Laki-laki & $85 \mathrm{~cm}$ \\
\hline Perempuan & $83,5 \mathrm{~cm}$ \\
\hline
\end{tabular}

(Bantas et al., 2013)

Tabel 5: Klasifikasi Berat Badan (BB)

Berdasarkan Indek Massa Tubuh

\begin{tabular}{ccc}
\hline No & $\begin{array}{c}\text { Indeks } \\
\text { Tubuh (IMT) }\end{array}$ & Katagori \\
\hline $\mathbf{1 .}$ & $<18.5$ & BB Kurang \\
\hline $\mathbf{2 .}$ & $18.5-24.9$ & BB Normal \\
\hline $\mathbf{3 .}$ & $25.9-29.9$ & BB Lebih \\
\hline $\mathbf{4 .}$ & $30-34.9$ & Obesitas I \\
\hline $\mathbf{5 .}$ & $35.0-39.9$ & Obesitas II \\
\hline $\mathbf{6 .}$ & $>39.9$ & Sangat \\
& & Obesitas \\
\hline
\end{tabular}

(WHO, 2016)

Tabel 6: Kriteria Diagnosis Sindrom Metabolik Menurut WHO,NCEP-ATP III, dan IDF

\begin{tabular}{|c|c|c|c|}
\hline $\begin{array}{c}\text { Unsur } \\
\text { sindrom } \\
\text { metabolik }\end{array}$ & WHO & NCEP-ATP III & IDF \\
\hline Hipertensi & $\begin{array}{c}\mathrm{TD} \geq 140 / 90 \\
\mathrm{mmHg}\end{array}$ & $\begin{array}{c}\mathrm{TD} \geq 130 / 85 \\
\mathrm{mmHg}\end{array}$ & $\begin{array}{c}\mathrm{TD} \geq \\
130 / 85 \\
\mathrm{mmHg}\end{array}$ \\
\hline Dislipidemia & $\begin{array}{c}\text { Plasma TG }> \\
150 \\
\text { mg/dLdanata } \\
\text { u HDL-C } \\
\mathrm{L}<35 \mathrm{mg} / \mathrm{dL} \\
\mathrm{P}<39 \mathrm{mg} / \mathrm{dL}\end{array}$ & $\begin{array}{c}\text { Plasma TG }> \\
150 \mathrm{mg} / \mathrm{dL}, \\
\text { HDL-C } \\
\mathrm{L}<40 \mathrm{mg} / \mathrm{dL} \\
\mathrm{P}<50 \mathrm{mg} / \mathrm{dL}\end{array}$ & $\begin{array}{c}\text { Plasma } \\
\text { TG }> \\
150 \\
\mathrm{mg} / \mathrm{dL} \text {, } \\
\mathrm{HDL}- \\
\mathrm{C} \\
\mathrm{L}<40 \\
\mathrm{mg} / \mathrm{dL} \\
\mathrm{P}<50 \\
\mathrm{mg} / \mathrm{dL} \\
\text { Atau } \\
\text { dalam } \\
\text { pengob } \\
\text { atan } \\
\text { dislipid } \\
\text { emia }\end{array}$ \\
\hline Obesitas & $\begin{array}{c}\text { IMT }>30 \\
\mathrm{~kg} / \mathrm{m}^{2} \text { dan } \\
\text { atau rasio } \\
\text { perut-pinggul } \\
\mathrm{L}>0.90 \\
\mathrm{P}>0.85\end{array}$ & $\begin{array}{c}\text { Lingkar } \\
\text { pinggang } \\
\mathrm{L}>102 \mathrm{~cm} \\
\mathrm{P}>88 \mathrm{~cm}\end{array}$ & 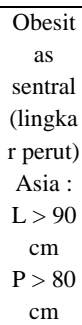 \\
\hline $\begin{array}{c}\text { Gangguan } \\
\text { Metabolism } \\
\text { e Glukosa }\end{array}$ & $\begin{array}{c}\text { DM tipe } 2, \\
\text { TGT atau } \\
\text { GDPT }\end{array}$ & $\begin{array}{c}\text { GD puasa }>110 \\
\mathrm{mg} / \mathrm{dL}\end{array}$ & $\begin{array}{c}\text { GD } \\
\text { puasa }> \\
100 \\
\mathrm{mg} / \mathrm{dL} \\
\text { atau } \\
\text { diagno } \\
\text { sis DM } \\
\text { tipe } 2\end{array}$ \\
\hline $\begin{array}{c}\text { KriteriaDia } \\
\text { gnosa }\end{array}$ & $\begin{array}{c}\text { DM tipe } 2 \\
\text { atau TGT dan } \\
2 \text { kriteria di } \\
\text { atas. Jika } \\
\text { toleransi } \\
\text { glukosa } \\
\text { normal, } \\
\text { diperlukan } 3 \\
\text { kriteria. }\end{array}$ & $\begin{array}{c}\text { Minimal } 3 \\
\text { kriteria }\end{array}$ & $\begin{array}{l}\text { Obesit } \\
\text { asSentr } \\
\text { aldan } 2 \\
\text { kriteria } \\
\text { di atas }\end{array}$ \\
\hline
\end{tabular}


Keterangan: $\mathrm{TD}=$ TekananDarah; $\mathrm{L}=$ Laki-laki; $\mathrm{P}=$ Perempuan; $\mathrm{TG}=$ Trigliserida; HDL-C = Kolesterol HDL; IMT = IndeksMasaTubuh; DM = DiabetesMelitus; TGT $=$ Toleransi Glukosa Terganggu; GD = Gula Darah; GDPT = Glukosa Darah Puasa Terganggu. (Bimandama \& Soleha, 2016)

\section{SIMPULAN}

Berdasarkan hasil dan data yang telah dilampirkan dapat disimpulkan bahwa dengan terbentukkan kader terlatih dalam melakukan screening Sindrome metabolic dapat memberikan pengetahuan dan wawasan serta dapat memberikan pelayanan kesehatan mampu memotivasi pengurus maupun peserta majlis taklim agar sadar kesehatan. Hasil dari pemeriksaan yang dilakukan kader pada peserta majlis taklim memiliki resiko kasus sindrome metabolik sekitar 60\%, dimana prosesntase ini menyatakan bahwa peserta majlis taklim akan sangat rentan mengidap penyakit kardiovaskular. Sehingga kader terlatih harus bisa rutin dalam melakukan screening sindrom metabolik, pemberian edukasi cara pencegahannya serta budaya hidup bersih dan sehat.

\section{DAFTAR PUSTAKA}

Amin, M. Al, \& Juniati, D. (2017). Klasifikasi kelompok umur manusia. MATHunesa, 2(6), 34. https://media.neliti.com/media/pub lications/249455-none 23b6a822.pdf.

Amir, S. M. J. (2015). "L'homme propose, mais dieu dispose." Notes and Queries, s6-VIII(184), 7. https://doi.org/10.1093/nq/s6VIII.184.7-b.

Bantas, K., Yoseph, H. K., \& Moelyono, B. (2013). Ukuran Lingkar Pinggang Optimal untuk Identifikasi Sindrom Metabolik pada Populasi Perkotaan di Indonesia. Kesmas: National Public Health Journal, 7(6), 284. https://doi.org/10.21109/kesmas.v7 i6.39.

Bimandama, M. A., \& Soleha, T. U. (2016). Hubungan Sindrom Metabolik dengan Penyakit Kardiovaskular. Jurnal Majority, 5(2), 49-55.

Jafar, Nurhaedar. (2012). Sindroma metabolik dan epidemiologi. Respitory Universitas Hasanuddin Makasar. 2(1),71-78.

Lasmadasari, N. (2016). Studi Pravalensi dan Faktor Risiko Sindrom Metabolik Pada Nelayan di Kelurahan Malabro. Jurnal MKMI, Vol. 12 No 2.

Nurzakiah, Hadju, V., Jafar, N., Indriasari, R., Sirajuddin, S., \& Amiruddin, R. (2021). Literature Review: Pengaruh Pola Makan Terhadap Sindrom Metabolik. ANNUR: Jurnal Kajian Dan Pengembangan Kesehatan Masyarakat Website, 1(2), 215224.

Setiadi, A. P., \& Halim, S. V. (2018). Penyakit Kardiovaskular Seri Pengobatan Rasional. 204.

Soegondo, S., \& Purnamasari, D. (2010). Sindrom Metabolik. Dalam: Sudoyo, Dkk. Buku Ajar Ilmu Penyakit Dalam. ..., 4, 88- 
93.http://scholar.google.com/schol

$\operatorname{ar} ? \mathrm{hl}=\mathrm{en} \& \mathrm{btnG}=$ Search\&q=intitle:

Sindrom+Metabolik.

WHO. (2016). Fact Sheet

Cardiovascular Diseases (Cvds).

Diambil Dari:

Www.Who.Int/Mediacentre/Factsh

eets/Fs317/En (Diakses Pada:

01/02/2017). 10:33.

Yusfita, Lailiyah Yusna. (2018).

Hubungan Perilaku Sedentari

Dengan Sindrom Metabolik Pada

Pekerja. The Indonesian Journal of

Public Health, Vol 13 No 2. 